\title{
Application of Theories, Techniques, Methods and Approaches to Develop Second Language Skills-a Study Based on Transition From Schooling to College
}

\author{
K. Jeya Gowri ${ }^{1 *}$, M. Ilankumaran ${ }^{2}$ \\ ${ }^{l}$ Research Scholar, Department Of English, Noorul Islam Center For Higher Education, Kumaracoil, Kanyakumari (Dist), Tamil Nadu, \\ India. \\ ${ }^{2}$ Professor, Department Of English, Noorul Islam Center For Higher Education, Kumaracoil, Kanyakumari (Dist), Tamil Nadu, India. \\ *Corresponding Author E-Mail:Jgowri427@Gmail.Com
}

\begin{abstract}
English is not just an official language in India, but also the language of mediation, higher education, science and technology. It is stated that India follows an improper curriculum pattern which is clear in the case of English language teaching, because the concept is failure in attaining the supreme result over the proficiency in language. Therefore, English Language Teaching and Learning in India is considered to be low in quality, according to the Indian Educational System. This hindrance can be ignored through proper curriculum pattern. The objective of this paper is to identify the connection between behaviour, anxiety and enthusiasm of high school and tertiary level students in learning English and obtaining the proficiency in second language skills. Second Language Learners fail to acquire the basic verbal skills from the school level. For the positive transition from the tertiary to the college, there should be a strong motivation from the side of education system as well as the people around the students. According to Vincent Tinto there are three stages that the students encounter in their academic life, they are separation, transition and incorporation. The paper also explores the transition period of the students psychologically, and offers remedial measures to come out of the confusion. It explores the theories, techniques, methods and approaches for imparting the second language skills during the transitional period of the students. The education system, adult learning and transition theories, problems and challenges have also been discussed in the paper.
\end{abstract}

Keywords: Language teaching, transition, challenges, communication, theories, proficiency, transitional dilemma.

\section{Introduction}

The period of transition is the crucial phase in the academic life of the students. It is important because, it is the stage for the students to turn out from the level of dependence to independence. Once they come out of the transitional dilemma, they will feel from the constraint academic life to the most responsible and an independent adult. Every phase of educational as well as career life considers English language learning as vital factor to carry out the successful life. Students face different kinds of learning situations at the levels of schools and colleges. In general, language is taught based on different requirements and aspects. Schools focus on to nurture the language in the aspect of tutoring or training the students for exam.

Colleges focus on teaching language in a practical way by equipping the skills of the students' need of employment. Students have various attitude towards learning the language on the basis of various factors and reasons. Moreover, learning the language at school level is totally different from college. The students in school have the most typical tension of memorizing things and present them in the exam. Meanwhile, in college, they could feel the transformation in learning the language, in the aspect of atmosphere as well in the way of learning. This paper critically appraises the factors encountered by the students when they face the new environment in college. Beyond that, there are certain barriers that affect the students from learning the language. The crucial method of teaching the language in a practical way and the role of teachers have also been discussed in this paper. This paper aims at exploring the problems of teaching English communication skills during the period of transition from schooling to college education.

The research article stresses the need of developing language skills at the school to college level. Developing students' language competency is one of the main responsibilities of a teacher of English. It is possible that some of the students have the feeling of fear or anxiety of committing mistakes while communicating in English. It is true that they could manage and control their nervousness of communication to some extent. The main question to be addressed here is the view of the ELT teachers, the tasks and duties in connection with the transition and the trials learners face in a language classroom. The factors and challenges are to be analyzed from the perspective of the transitional students' acquisition of communication skills.

\section{Education System}

Sir Charles Wood in 1834, specified that English language is essential to enter the higher academic studies but there is no response. In 1835, Lord Macaulay introduced the language through the educational policy "Minute of Education". In the urban areas, the role of the language develops in the field of education because of its importance. In 1964, Indian Education Commission also known as Kothari Commission, introduced the 
general pattern of the policy to develop the study of the English language in India. This commission proposed the structural approach for teaching English in India. The importance of English language in India started here through the building of English medium schools.

The traditional teaching methodology does not replace modern teaching except learning through technology based teaching. The current education system forces the students to be competitive by killing the creativity. The students are prepared to be ready to get good marks. In this approach, the creativity of the students with different abilities was lost to pay attention by the mentors. The school trains the students for competition. There is no scope for creativity, inventions and self-learning. Albert Einstein's famous quote "Everybody is a genius. But if you judge a fish by its ability to climb a tree, it will live its whole life believing that it is stupid." The development in every fields is considered vital for the better future. In this case the classroom and teaching methodology do not progress from the traditional method. Education system contains so many different tables. It requires single board with a solid study.

\section{Theories and Techniques}

Adults experience a distinct exposure in learning through activities. Regarding adult developmental theories, there are two kinds, one is the theories of adult development which are considered to be connected with the stages of a particular age (Levinson, 1978). Age factors such as young, mid and older adulthood (Erikson, 1968; Valliant, 1977). On the other hand, it is considered that the transition in adult developmental phase occurs not by age factor but by the change in the atmospheric or the cultural situations. (Fiske, 1980; Pearlin, 1980; Schlossberg, 1984)

\section{Adult Learning Transitions}

There are three extents in the adult transition theory, namely, the behavioural, convictional and psychological systems. Mezirow relies on the point, that the transformative learning consequences in perplexing dilemma which shows the transformation over the period of time. Mezirow enlightened the perceptions as trails or traces,

- Perplexing dilemma

- Self-analysis

- Feeling of alienation

- Revealing dissatisfaction to others

- Explaining possibilities of different behaviour

- Structuring the self-confidence in innovative ways

- Scheduling the progress of achievement

- Implementing novel plans wisely

- Investigating different roles

- Recuperation

\section{Adult Learning and Psychology}

Knowles claims the andragogical approach for the teachers to nurture their skills. On the substance of the andragogical approach, it is categorized into a set of assumptions that is essential for a teacher to understand the adult learners.

- Before the commencement of learning, adult should understand the necessity of learning.

- $\quad$ The psychological need of the adult should be handled by others to motivate them for self-direction.

- Adult gathers learning through experience which could be an abundant material for learning.

- The eagerness of children to learn basically depends on the biological progress and the factor of academicals stress. In adult, it is the purpose to accomplish societal roles.
- Children, habituated with the orientation of subjectcentred learning while adults partake the learning with the problem-centred orientation.

- The powerful motivators in adults are internal.

\section{Cognitivism}

The Cognitive approach has two norms, they are:

- The system of memory is a dynamic systematized processor of information

- In learning, the previous knowledge acts as a vital part to make a comparison and to recognise the information

Cognitivism primarily expounds brain based learning rather than the behaviourism. As it highlights the brain based learning, it depends on the memory of human and it is working to promote learning. This theory focuses on the short term and long term memory of the learners.

\section{The Implementation of Piaget's Cognitive Development Theory in The Classroom}

- The instructor helps the students to develop the learners' cognitive skills. The tasks allotted for the pupils is carefully chosen to be appropriate to the stage of the student.

- The teacher motivates the student to independently explore learning over discovery.

- The tutor allows the students to learn from others which paves way for the learners to learn from different perspectives and gather many views and information from each student.

- Piaget claims that the curriculum amended has to be adaptable to the needs and stages of the individual learners.

\section{Behaviourism}

B. F. Skinner primarily developed this theory. It focuses mainly on the behaviours. Behaviourism is the learning acquisition of new behaviour through training. In behaviourism, there are three different basic norms. They are:

i. Learning is expressed using a transformation in behaviour.

ii. Behaviour is shaped through environment.

iii. The ideologies of proximity and support are the crucial learning process in behaviourism.

Training process in behaviourism consists of two types: Classical Conditioning and Operant Conditioning. A reflex response to a stimulus in behaviour is called Classical Conditioning: The strengthening of the behaviour through punishment or reward is called Operant Conditioning: Skinner developed the Operant Conditioning theory which is known as Radical Behaviourism. Behaviour works on the environment. The consequent of behaviourism may be in strengthening which intensifies the credibility of the recurring behaviour. Punishment reduces the credibility of the recurring behaviour. Punishment is not applicable to the reinforcement of the behaviour

Techniques is one of the tools used in the teaching-learning process which is in point of fact used to implement the method in the process. The strategies for teaching the four skills in English are as follows:

Teaching Listening Skills: The listening process aims at consisting of auditory input accepting the relevant information rather than word by word comprehension. The listening skills of the students are developed by the practice of making announcements, homework, explaining the content and tests in Target Language.

Metacognitive Strategies: There are three things to listen before planning the listening task. 
- $\quad$ Purpose to be decided in advance

- Deciding the level of the linguistic background

- Determining the focus of the task

Things to be noted during and after listening

- Verifying and checking for the inaccurate presumptions

- Listening again for the clear understanding

- $\quad$ Asking for help

Things to be noted after listening

- Evaluating the comprehension

- Evaluating the progress in listening skills

- Deciding whether the technique is applicable for the task

- Modifying if changes needed in the strategy

\section{Practice Listening Through Authentic Material and} Situation

Using the reliable materials and situations, learners train themselves in listening the language.

\section{Materials}

- Television and radio programmes

- Public announcement addresses

- Lectures and speeches

- Movie clippings

- Conversation in different situations

- Telephone recordings of customer service

\section{Techniques}

- To understand the specific information, students have to be helped to identify and understand the message

- Pupils have to be helped to outline the sequence using the content words by framing questions such as who what, where, when in the case of news stories

- Learners have to be helped to identify key words or phrases while listening to the content

\section{Teaching Speaking Skills}

Language learners considers the ability to speak and converse as the fluency and the measure of knowing the language. The progress in the spoken communication is regarded as the accomplishment in the language learning and acquiring the speaking skills. There are three areas of knowledge in speaking that a learner should be aware in acquiring the speaking skills. They are:

- Mechanics: The mechanics of speaking involves the learning of pronunciation, grammar and vocabulary which entails using the words in order with correct pronunciation.

- Functions: Function of speaking brings about the communication via interaction and transaction, i.e. interaction refers to the exchange of message, depending on the situation, while transaction aims at the clarity of message.

- Social and cultural rules and norms: It takes an account of understanding and the rate of speech between the speakers and their relative roles.

\section{Activities for Speaking Skills}

Traditional classroom paves way for controlled communication because it provides activities through drills. Asking questions and answering them are done, thus it does not cover up the real life situations. To attain speaking skills through activities, all that the learners need is error correction and opportunities. Accordingly, in authentic speaking, activities implicate a purpose and an information gap.

\section{Structured Output Activities}

Structured Output Activities comprise two common kinds, they are information gap and jigsaw activities. These tasks enable the readers to find the missing information, it paves for real communication.

\section{Activities of Information Gap}

The Information Gap activities can be done the practice of two persons. It is prepared by filling time schedules, describing pictures, appointments, etc.

\section{Activities of Jigsaw}

Jigsaw activities set with the activities of several partners. These activities comprises the puzzle task. In this, the learners have to place the puzzles in the right order. The puzzle may be a story, a conversation or a comic strip which allows the learners to the authentic conversation with the practice of a brief sentence.

\section{Communicative Output Activities}

Communicative output activities includes most common activities such as role plays and discussions. In role play, the learners practice the language by transmitting the roles and engage themselves outside the classroom. This practice develops their sociolinguistic proficiency. The language is used in right situations by the learners.

\section{Teaching Reading Skills}

Reading is a decoding process. Readers use strategies for the effective reading. It is a skill which uses knowledge to gain ideas and information. The strategies for the quick and effective reading include:

- Previewing: Previewing is a strategy, which can be used by reviewing the headings, titles and photo captions to get the outline structure and content of the reading.

- Predicting: Prediction is the main source in this strategy, the readers predict the content by the type of text and author.

- Skimming and Scanning: Identifying the structure of the text by a quick survey to acquire the central idea of the content.

- Guessing: In this strategy, the unknown words from the content is guessed by the prior knowledge of the reader rather than looking for the meaning of the words.

- Paraphrasing: It is restating the ideas and information from the text.

These are the reading strategies that the learners of language use to gain self-reliance in the ability to read language.

\section{Teaching Writing Skills}

In writing skills, an individual has to be clear in two skills- to express the ideas in brief and clear and the command over the language. The objectives of writing skills are:
i. To have an interest in writing
ii. To be smooth and ease in writing
iii. To develop confidence 


\section{Procedures for Teaching Writing}

The teaching of composition is the best technique for teaching writing skills. The result of the applied activity of teaching reading skills has to be recorded and the selected composition has to be carefully chosen according to the ability of the learners.

The four activities in writing are:

- Arranging and planning the work

- Paragraph construction

- Constructing and ordering the sentences

- Idioms and vocabulary

\section{Guided Composition}

In this activity, ideas are provided to the learners. The objective of this task is to eradicate mistakes in writing and allow the learners to write independently. For instance, a picture or an outline is guided to the learners which promotes them to be connected in narrative writing.

\section{Free Composition}

Free composition is open-ended. It gives freedom to the learners for working on with their own perspective and ideas. The topic may be chosen from personal to general.

\section{Picture Composition}

Picture composition is writing the composition with the help of a picture. The picture is shown with the aid of blackboard and charts. This activity helps the learners to understand the meanings of words. It stimulates the curiosity and interest in learners.

\section{Methods and Approaches}

Method is an organized language material which involves presentation, progression and repetition. An approach deals with the nature of the language teaching and learning.

\section{Community Language Learning}

In Community Language Learning, the learners work together as a community to learn the language. In this method, the teacher performs as a counsellor and a paraphraser and the learner acts as a team. It makes ease for the students to come out of the fear. This method vastly depends on the Krashen's Cognitive and Monitor theory.

There are certain features of Community Language Learning (CLL). They are:

i. CLL allows the teachers unconnected from the students

ii. Mother Tongue (MT) is used for the comfortable convenience of the learners

iii. Community is promoted to build the level of trust and courage

iv. This method uses the reliable materials for the learners

\section{Silent Way Method}

The Silent way method rely on teaching that is secondary to learning. In the classroom, the teacher remains silent and the students communicate with each other. This activity is considered to be an active and creative to the learners in which they can act as an active participator rather than a passive listener. The students become independent in learning through this method.

The main features of the Silent Way Method are:

i. The learning is enabled through the learner centred activities where learner creates or discovers learning. ii. The atmosphere for learning the language is nonthreatening because the teacher becomes the silent instructor.

iii. There is no condemnation of the teachers, the students correct their errors through peer correction and selfcorrection.

\section{Total Physical Response}

The method, Total Physical Response (TPR) is based on the management of action and speech. It is connected with the tracing of the memory. The chief purposes of Total Physical Response are:

- The base of learning the language is formed through listening ability.

- Learners learn the language by doing things.

- Learners learn the meaning of the Target Language (TL) over actions.

\section{Cognitive Approach}

The methods under the Cognitive approach are theoretical rather than other methods. There are several methods that come under cognitive approach and one of the methods is Training by Intelligent Tutorial System (ITS).

\section{Criteria of Intelligent Tutorial System (ITS)}

The instructions are selected to the appropriate level of the students. It monitors the beginners. The system in this approach is text-based. The tutorial programme is evaluated. The teaching methodology to the students vary depending on the information. The tutorial system is interactive. It evaluates the knowledge of students. The system detects the problem of the students.

\section{Transition Period}

Vincent Tinto says that transition period involves separation, transition and incorporation. It is a distinct period that the students recognize while moving to college life. Vincent Tinto also says that "Transition" is different from change. Change is external and visible. A transition is internal and less visible, the process one goes through mentally while facing a big life change". The followings are those of the factors which the students encounter during the transition period with the comparison of the two levels that is the tertiary and the college level.

- Students have an internal interest in the subject chosen to improve their career skills for job opportunities. In school, they are prepared to get high marks. Thus, they lack self-learning and motivation, they were not exposed to the basic etiquette for career skills.

- The students who were straight from the tertiary level to the college feel unexpected, staggered and not ready to survive in the university.

- An entirely different environment, situation is difficult for most of the students to adapt themselves at the initial stage.

- Schools were conventional and never promote the students to be independent, on the other hand, learning is given importance at university or college level.

- Students in school were made to be given importance to the rote memorization and in college, the students get matured by the nurture of the learning process by taking their responsibilities in spending the free time for autonomy learning.

- In schools, autonomy in learning has never been considered important and hence the students were dependant on spoon feeding of the teachers. In this circumstance, the medium of instruction is not a matter 
and the subject content also is not a matter for the students which results in rote memorization. This type of learning and teaching does not promote any learners to be proficient in English language as well as the subject content.

\section{Guidance for Teachers and Students in Transitional Dilemma}

Transition in college life is difficult for the students to handle, as it exposes an entirely novel environment with different academic policies. Teachers have to focus on all sets of students, and not only the intelligent and average students. Teachers have to give equal care to all students so as to create a healthy relationship. Weak students have to get more attention from the teachers. Punishments need not be given in the classroom, as it would affect the students psychologically. Beyond that, it is in the hands of the teachers to create the teacher-friendly environment. A teacher has to motivate the students to communicate in English, thereby they will get enough chance for that. The teacher should make the students participate in peer learning, and other activities to develop communication skills. Thus, the teacher can lead the students to feel comfortable from the transitional dilemma.

\section{Problems of the Second Language Learner}

English is not a native language to the Indians. First language acquisition is the natural process which the child acquires through internalization of the structure of the language. These patterns of language become familiar to the native people from the mother and the people in the surroundings while growing up. At the same time, a child acquires the phonology, morphology and syntactical patterns without any effort rather just by casually observing. In the case of second language, it is not acquires from the child, it has been imposed from the schools. The child is not learned the language from the mother or the surroundings but by the teachers in schools starting from the alphabet to the grammar.

The problems that every student encounters during the language imposition is that language is taught from the basic of grammar without any practical exposure. It is being learnt by the students without any awareness. Some students have the family support in developing the language skills but in other cases some students may be the first generation learners so it is impossible for them to practice it at home to develop their language. In this circumstance, they lack confidence. English becomes a boring subject just because it is not properly taught in classes. Not all teachers to be blamed. Some teachers skip the grammar portions just because of the lack of grammar knowledge. The following are the factors which affect English Language Teaching.

\section{Problems and Challenges in ELT}

Indian speakers of English face the difficulties in speaking the fluent English. The influence of the mother tongue is the main factor. The learners of second language, face the problems of poor vocabulary, lack of confidence, fear and nervousness, lack of grammatical knowledge, lack of the knowledge of body language, educational system without much focus on speaking skills and no provision of separate English classes in schools.

Speaking is the crucial and fundamental mode of communication in the human society. It is these expression of ideas, thoughts, feelings, etc. In schools, the focus has been laid largely on texts rather than on communication skills. Maximum students do their schooling in the mother tongue and the unusual change in the medium of instruction corner them in the state of confusion. While hunting for a job, this crucial stage poses as a hefty block. In most of the job interviews, people are selected for their good command over English. Even most knowledgeable people could not express their ideas in English and get rejected in interviews due to the poor command over the language.

Another important problem associated with the English language teaching is the presence of large number of learners. The examination system is more achievement oriented than performance oriented. In addition, there is less time for the teacher to focus on individual student's exact language requirements of reading skills, note making skills, writing skills and speaking skills.

\section{Cognitive Challenge}

The critical thing that the students face in higher education is cognitive challenge. When the students enter tertiary level, they are expected to be scholarly in thinking and academically in writing. Being experienced in transition, there are certain challenges that the students face in learning, they are the new vocabulary, new concepts, and scholarly level perceptions in language skills.

\section{Conclusion}

In a situation of second language learning, the two important factors are the teacher and the student. A class may have numerous students with various capacities, it is difficult task of the teacher to handle the students with different abilities. Even there are a number of college students with poor knowledge in language, they are in need to be taught with the elementary lessons. The methods employed in schools as well as in colleges is inappropriate to their standard levels. The transition of the students in learning the language starts from here. The students find difference in group behaviour, organisational functioning, gender difference and emotional contagion. These are the struggle of the students who move from high school to tertiary level. Teachers have to give attention to all sets of learners, not only the average and intelligent students. They have to give equal care to all students so as to generate a healthy relationship. The weak students have to get more care from the teachers. Penalties need not be done in the classroom, as it would affect the students psychologically. Beyond that, it is in the hands of the teachers to create the teacher-friendly environment. A teacher has to motivate the students to attain their language skills thereby they will get enough chance for that. The teacher should make the students participate in peer learning, and other activities to develop communication skills. Thus, the teacher can make the students feel comfortable from the transitional dilemma.

\section{References}

[1] Abilasha R \& Ilankumaran M, "Incarnation of ICT in English Language Teaching", Research Journal of English Language and Literature, Vol.2, No.4, (2014), pp. 216-220.

[2] Stalin A \& Ilankumaran M, "Challenges and Strategies of Teaching English as a Second Language: An Overview", New Trends in Language and Literature, (2017), pp.5-7.

[3] Aggarwal JC, History of Modern Indian Education, Noida: Vikas Publishing House Pvt Ltd, (2007).

[4] Akbari Z, "Current Challenges in Teaching/Learning English for EFL learners: The Case of Junior High School and High School", Procedia Social and Behavioral Science, Vol.199, (2015), pp.394 401.

[5] BECTA, "What Research Says about Interactive Whiteboards", Coventry, UK: BECTA. Vol.12, (2003).

[6] Ellis R, The Study of Second Language Acquisition, Oxford University Press, Oxford, (1994).

[7] Levinson DJ, The Seasons of a Man's Life, New York, NY: Ballantine, (1978)

[8] Schlossberg NK, Counselling Adults in Transition, New York, NY: Springer, (2006) 
[9] Sharm A, "Interactive Whiteboard Technology in English Language Teaching Classrooms in India", Language in India, Vol.12, No.1, (2012).

[10] Tinto V, "Stages of Student Departure: Reflection on the Longitudinal Character of Student Leaving", Journal of Higher Education, Vol.59, No.4, (1988), pp. 438-455.

[11] "Limits of theory." Journal of Higher Education, Vol. 59, No.4, 1982, pp. 438-455.

[12] Varghese PC, Teaching English as a Second Language, Sterling Publishers, New Delhi, (2016).

[13] Wood FT, An Outline History of the English Language, Macmillan. Delhi, (2013).

[14] Fook CY \& Sidhu GK, "Investigating learning challenges faced by students in higher education", Procedia - Social and Behavioural Sciences, Vol.186, (2015), pp.604-612. 